TITLE:

\title{
Platinum loaded sodium tantalate photocatalysts prepared by a flux method for photocatalytic steam reforming of methane
}

AUTHOR(S):

Yamamoto, Akira; Mizuba, Shota; Saeki, Yurina; Yoshida, Hisao

\section{CITATION:}

Yamamoto, Akira ... [et al]. Platinum loaded sodium tantalate photocatalysts prepared by a flux method for photocatalytic steam reforming of methane. Applied Catalysis A:

General 2016, 521: 125-132

\section{ISSUE DATE:}

2016-07-05

URL:

http://hdl.handle.net/2433/250241

\section{RIGHT:}

(c) 2016. This manuscript version is made available under the CC-BY-NC-ND 4.0 license http://creativecommons.org/licenses/by-nc-nd/4.0/.; This is not the published version. Please cite only the published version.; この論文は出版社版でありません。引用の際には 出版社版をご確認ご利用ください。 


\title{
Platinum loaded sodium tantalate photocatalysts prepared by a flux method for photocatalytic steam reforming of methane
}

\author{
Akira Yamamoto $^{\mathrm{a}, \mathrm{b}}$, Shota Mizuba ${ }^{\mathrm{a}}$, Yurina Saeki ${ }^{\mathrm{a}}$ and Hisao Yoshida ${ }^{\mathrm{a}, \mathrm{b} *}$
}

\section{Affiliation and full postal address}

a Department of Interdisciplinary Environment, Graduate School of Human and Environmental Studies, Kyoto University, Yoshida Nihonmatsu-cho, Sakyo-ku, Kyoto 606-8501, Japan

${ }^{b}$ Elements Strategy Initiative for Catalysts \& Batteries (ESICB), Kyoto University, Kyotodaigaku Katsura, Nishikyo-ku, Kyoto 615-8520, Japan

\section{Corresponding authors}

Professor Hisao Yoshida

Department of Interdisciplinary Environment, Graduate School of Human and Environmental Studies, Kyoto University, Yoshida Nihonmatsu-cho, Sakyo-ku, Kyoto 606-8501, Japan

Tel: +81-75-753-6594 Fax: +81-75-753-2988

E-mail address: yoshida.hisao.2a@kyoto-u.ac.jp 


\section{ABSTRACT}

Lanthanum-doped sodium tantalate samples $\left(\mathrm{NaTaO}_{3}: \mathrm{La}\right)$ were prepared by a flux method using a sodium chloride flux with various parameters, such as presence or absence of the flux, solute concentration, hold temperature, and amount of lanthanum doping. SEM images showed cubic and rectangular shapes for the samples prepared by the flux method, somewhat rounded shape for the sample prepared in the absence of the flux, and large particles for the sample without lanthanum doping. Among the parameters, the lanthanum doping and solute concentration much influenced the crystallites size of the $\mathrm{NaTaO}_{3}: \mathrm{La}$ samples. Most of these $\mathrm{NaTaO}_{3}: \mathrm{La}$ samples loaded with platinum cocatalyst exhibited the photocatalytic activity in the photocatalytic steam reforming of methane around room temperature. Among them, the highest activity was obtained by the $\mathrm{Pt} / \mathrm{NaTaO}_{3}: \mathrm{La}$ sample prepared by the flux method with moderate solute concentration, enough high hold temperature, and moderate amount of platinum and lanthanum doping. A positive correlation was found between the crystallite size and the photocatalytic activity. When we compared the catalysts having the same crystallite size, the sample prepared by the flux method showed higher photocatalytic activity than the catalyst prepared without the flux. It is suggested that the difference in the shape of particle would be important factor for the photocatalytic activity.

KEYWORDS: photocatalytic steam reforming of methane, hydrogen production, sodium tantalate, flux method, molten salt method 


\section{INTRODUCTION}

Hydrogen is one of the clean and oncoming energy sources, and its production technology have been developed and investigated by many researchers. As a source of hydrogen, methane is an attractive hydrogen source because of the highest $\mathrm{H} / \mathrm{C}$ values among hydrocarbons, and it is one of the most abundant natural resource as well as a main component of renewable biogas. Methane can be catalytically converted to hydrogen by steam reforming of methane, which is the practically employed method for the hydrogen production. The overall chemical equation of the steam reforming of methane with successive water-gas shift reaction can be shown in eq. 1 .

$$
\mathrm{CH}_{4}+2 \mathrm{H}_{2} \mathrm{O} \rightarrow 4 \mathrm{H}_{2}+\mathrm{CO}_{2} \quad \Delta \mathrm{G}_{298 \mathrm{~K}}^{\ominus}=113.5 \mathrm{~kJ} \mathrm{~mol}^{-1}
$$

This is a highly endergonic reaction; therefore, high temperature, typically more than $1073 \mathrm{~K}$, is necessary to promote the reaction even in the presence of catalysts. The high temperature operation causes several problems such as the large energy consumption, the irreversible carbon formation, and the necessity of expensive reactor. Thus, lowering the operation temperature has been highly desired in the seam reforming of methane.

Utilization of photocatalysts is expected to be a promising way for the development of the steam reforming of methane at low temperature [1-3]. A reaction between methane and water to form methanol and hydrogen was reported by Taylor et al. over La-doped $\mathrm{WO}_{3}$ under $\mathrm{UV}$ and visible light irradiation $[4,5]$ in an aqueous solution containing methyl viologen dichloride as an electron transfer reagent. Gondal et al. also reported the photocatalytic conversion of methane to methanol in a batch reactor using a visible laser $(514 \mathrm{~nm})$ and a $\mathrm{WO}_{3}$ catalyst [6]. However, these systems might not be suitable for hydrogen production. 
On the other hand, our group firstly reported the photocatalytic steam reforming of methane over heterogeneous photocatalysts using a gas mixture of methane and water around room temperature to produce hydrogen and carbon dioxide directly as shown in eq. 1, where the photoenergy was added to the system for compensation of the Gibbs free energy change of this reaction [7]. In other words, the utilization of photoenergy enables us to operate the reaction at low temperatures, which may solve the some problems mentioned above. Platinum-loaded titanium dioxide $\left(\mathrm{Pt} / \mathrm{TiO}_{2}\right)$ photocatalysts showed the activity at mild temperature under photoirradiation, and gave the stoichiometric ratio of the products $\left(\mathrm{H}_{2} / \mathrm{CO}_{2}=4\right)[7,8]$. Various photocatalysts have been developed for the photocatalytic steam reforming such as Pt-loaded La-doped $\mathrm{NaTaO}_{3}\left(\mathrm{Pt} / \mathrm{NaTaO}_{3}: \mathrm{La}\right)$ [7, 9], Pt-loaded $\mathrm{CaTiO}_{3}[10,11]$, Rh-loaded $\mathrm{K}_{2} \mathrm{Ti}_{6} \mathrm{O}_{13}[12,13]$, and Pt-loaded or Rh-loaded $\beta-\mathrm{Ga}_{2} \mathrm{O}_{3}$ [14]. It was also found that this photocatalytic reaction could be further promoted at higher temperature; i.e., thermal energy could assist this photocatalytic reaction, which promised further development [15]. However, their photocatalytic activities have been not enough yet, and the further improvement of the photocatalytic activity have been desired for the practical use.

Flux method (molten salt method) is effective for synthesis of high quality crystals (with high crystallinity), and the prepared crystals often have characteristic and uniformed shapes covered with particular flat facets. It is considered that the high crystallinity is an important property for the highly active photocatalyst because crystal defects are believed to function as recombination sites for excited electron and hole pairs. In addition to the crystallinity, the shape of the crystals or the particles is considered to be one of the key factors affecting the photocatalytic activity [16-19]. The crystal facets have been pointed out to help in the separation of photogenerated carriers (electrons and holes), 
which leads to the high photocatalytic activity [20-22]. The suppression of the recombination is one of the strategies to improve the photocatalytic activity. Up to date, a number of crystals with characteristic shapes were synthesized by flux methods and examined as photocatalysts [23-34].

In the present paper, a flux method was employed to prepare the $\mathrm{NaTaO}_{3}: \mathrm{La}$ crystalline samples and the photocatalytic activity was investigated in the photocatalytic steam reforming of methane.

\section{EXPERIMENTAL}

\subsection{Catalyst preparation}

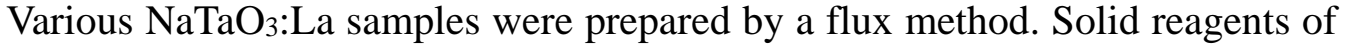
$\mathrm{Ta}_{2} \mathrm{O}_{5}, \mathrm{Na}_{2} \mathrm{CO}_{3}$ (Rare Metallic, 99.99\%), $\mathrm{La}_{2} \mathrm{O}_{3}$ (Kishida, 99.99\%), and $\mathrm{NaCl}$ (Kishida, 99.5\%) were used as-purchased. The mixture of $\mathrm{Ta}_{2} \mathrm{O}_{5}, \mathrm{Na}_{2} \mathrm{CO}_{3}, \mathrm{La}_{2} \mathrm{O}_{3}$, and $\mathrm{NaCl}$ was ground in an aluminum mortar for $15 \mathrm{~min}$, where the molar ratio of $\mathrm{Na}_{2} \mathrm{CO}_{3}$ to $\mathrm{Ta}_{2} \mathrm{O}_{5}$ was unity. Although it was reported that an excess amount of $\mathrm{Na}_{2} \mathrm{CO}_{3}$ in the mixture could compensate the volatile sodium and function as a flux [35], in the present study a stoichiometric ratio of $\mathrm{Na}_{2} \mathrm{CO}_{3}$ was added and $\mathrm{NaCl}$ was used as a flux, which can help us to discuss the role of a flux more clearly. The aimed amount of La was $0-5$ mol\%. The solute concentration of 5-90\% was defined as the following equation:

Solute concentration, $x$

$(\mathrm{mol} \%)=\frac{\mathrm{Amount} \text { of } \mathrm{NaTaO}_{3}(\mathrm{~mol})}{\text { Amount of } \mathrm{NaTaO}_{3}(\mathrm{~mol})+\mathrm{Amount} \text { of } \mathrm{NaCl}(\mathrm{mol})} \times 100$ 
The mixture was heated in a platinum crucible using an electric furnace with a heating rate of $200 \mathrm{~K} \mathrm{~h}^{-1}$ to various target temperatures (1073-1473 K, typically $1273 \mathrm{~K}$ ), successively heated at the same temperature (hold temperature) for $5 \mathrm{~h}$, and then cooled down once to $773 \mathrm{~K}$ at a cooling rate $100 \mathrm{~K} \mathrm{~h}^{-1}$ and then to room temperature without controlling the temperature. The obtained powder was dispersed in hot ion-exchanged water $(300 \mathrm{~mL}, 353 \mathrm{~K})$ and filtrated with suction to separate the powder from the flux. The washing procedure was repeated four times, and dried at $323 \mathrm{~K}$ overnight to obtain the $\mathrm{NaTaO}_{3}: \mathrm{La}$ sample. These samples are referred to as $\mathrm{NaTaO}_{3}: \mathrm{La}(x, T, y)$, where $x$ is the solute concentration defined in eq. 2, $T$ is the hold temperature, and $y$ shows the aimed amount of lanthanum doping (mol\%), if necessary. On the other hand, a reference sample were prepared without the flux in a solid state reaction method: the starting mixture except for the sodium chloride flux i.e., $\mathrm{Ta}_{2} \mathrm{O}_{5}, \mathrm{Na}_{2} \mathrm{CO}_{3}$, and $\mathrm{La}_{2} \mathrm{O}_{3}$, where the solute concentration $x$ corresponded to be 100, was ground well, heated with the same rate of $200 \mathrm{~K} \mathrm{~h}^{-1}$, maintained at $1273 \mathrm{~K}$ for $5 \mathrm{~h}$, and then cooled, followed by washing, in the similar way as mentioned above. This sample is referred to as $\mathrm{NaTaO}_{3}: \mathrm{La}(100,1273,2)$.

Platinum co-catalyst was loaded onto the prepared $\mathrm{NaTaO}_{3}: \mathrm{La}$ samples by an impregnation method. The sample was soaked in an aqueous solution of $\mathrm{H}_{2} \mathrm{PtCl}_{6}$ (Wako, $99.9 \%$ ), dried up and calcined at $673 \mathrm{~K}$ for $2 \mathrm{~h}$. The sample powder was granulated to the size of $300-600 \mu \mathrm{m}$ before the photocatalytic activity test. The Pt loaded sample is referred to as $\mathrm{Pt}(z) / \mathrm{NaTaO}_{3}: \mathrm{La}(x, T, y)$, where $z$ shows the loading amount of $\mathrm{Pt}(\mathrm{wt} \%)$.

\subsection{Characterization}

$\mathrm{X}$-ray diffraction (XRD) measurement was carried out at room temperature using a Shimadzu Lab X XRD-6000 using $\mathrm{Cu}$ K $\alpha$ radiation (40 kV, $30 \mathrm{~mA})$. The crystallite size 
was determined by the Scherrer equation using the full width at half maximum (FWHM) of the diffraction line at $2 \theta=22.8^{\circ}$ in the XRD patterns of $\mathrm{NaTaO}_{3}$. Scanning electron microscopy (SEM) images were recorded by a JEOL JSM-890. Diffuse reflectance (DR) UV-Visible spectrum was recorded on a JASCO V-670 equipped with an integrating sphere covered with $\mathrm{BaSO}_{4}$ reference. The band gap was estimated from the spectrum according to Tauc plot [36]. The specific surface area was estimated from the amount of $\mathrm{N}_{2}$ adsorption at $77 \mathrm{~K}$ measured using a Quantachrome Monosorb.

\subsection{Photocatalytic activity tests}

Photocatalytic steam reforming of methane was carried out with a fixed-bed flow reactor as described in our previous studies [7-9] Shortly, a mixture of the catalyst granules $(0.5 \mathrm{~g})$ and quartz sand $(1.2 \mathrm{~g})$ was put into a quartz reactor $(\mathrm{ca} .50 \times 20 \times 1$ $\left.\mathrm{mm}^{3}\right)$ and the reaction gas of $\mathrm{CH}_{4}(25 \%)$ and $\mathrm{H}_{2} \mathrm{O}(0.75 \%)$ with an argon carrier was introduced at a flow rate of $50 \mathrm{~mL} \mathrm{~min}{ }^{-1}$ without heating at atmospheric pressure. Light irradiation was carried out from a $300 \mathrm{~W}$ xenon lamp without using any optical filter, where the light intensity was measured to be $14 \mathrm{~mW} \mathrm{~cm}^{-2}$ in the range of $245 \pm 10 \mathrm{~nm}$. The outlet gas was analyzed by online gas chromatography with a thermal conductivity detector at an interval of ca. $30 \mathrm{~min}$. Since the sensitivity for $\mathrm{CO}_{2}$ in the argon carrier was low, the experimental error for the values of $\mathrm{CO}_{2}$ production rate was relatively large. 


\section{RESULTS AND DISCUSSION}

\subsection{Characterization}

Fig. 1 shows XRD patterns of the $\mathrm{Pt} / \mathrm{NaTaO}_{3}: \mathrm{La}$ samples prepared by the flux method at various hold temperatures. A diffraction pattern of $\mathrm{Ta}_{2} \mathrm{O}_{5}$ (ICSD No. 9112) [37] was observed for the sample heated at $1073 \mathrm{~K}$ (Fig. 1a), which indicates that the temperature is not enough to generate the $\mathrm{NaTaO}_{3}$ phase as desired. At this temperature, $\mathrm{Na}_{2} \mathrm{CO}_{3}$ would be decomposed to form $\mathrm{Na}_{2} \mathrm{O}$ through decarbonation. Considering the melting points of the $\mathrm{NaCl}$ flux to be $1074 \mathrm{~K}$ [38], the hold temperature and time (1073 $\mathrm{K}, 5 \mathrm{~h}$ ) would not be enough for $\mathrm{Na}_{2} \mathrm{O}$ to react with the $\mathrm{Ta}_{2} \mathrm{O}_{5}$ particles. By heating over $1173 \mathrm{~K}$, the clear diffraction lines of the $\mathrm{NaTaO}_{3}$ phase (ICSD No. 980) [39] appeared without any impurity phase. It was revealed that the higher temperature than $1173 \mathrm{~K}$ was necessary to generate the $\mathrm{NaTaO}_{3}$ crystallites in this method.

Fig. 2 shows the XRD patterns of the Pt/NaTaO $3: \mathrm{La}$ samples prepared by the flux method at the hold temperature of $1273 \mathrm{~K}$ with various solute concentrations. For all the samples (Fig.2a-f), the diffraction patterns were assignable to that of $\mathrm{NaTaO}_{3}$, and any impurity phase was not observed. The sample without La doping also showed the diffraction lines from $\mathrm{NaTaO}_{3}$ crystallites (Fig. 2g).

XRF measurements on the $\mathrm{Pt} / \mathrm{NaTaO}_{3}: \mathrm{La}(x, 1273,2)$ samples confirmed that the amount of the doped La was almost the same as the desired value (Table 1 entries 7-12, 16, 17). This clearly indicated that all the La cations introduced were doped inside the bulk or on the surface of the $\mathrm{NaTaO}_{3}: \mathrm{La}$ samples, which means the La cations were neither captured in the $\mathrm{NaCl}$ matrix nor released from the $\mathrm{NaTaO}_{3}$ particles by washing during the preparation. 
As for the samples prepared with higher hold temperature than $1173 \mathrm{~K}$, the average size of the $\mathrm{NaTaO}_{3}$ crystallites was estimated from the diffraction line at $22.8^{\circ}$ by using Scherrer equation and listed in Table 1. The crystallite size did not depend on the hold temperature (Table 1, entries 2-6). On the other hand, the solute concentration and the presence of the flux much affected the crystallite size; the size of the $\mathrm{NaTaO}_{3}$ crystallites increased with an increase of the solute concentration (Table 1, entries 7-11) and the sample prepared without the flux had the largest crystallite size among these samples (Table 1, entry 12). This means that the $\mathrm{NaCl}$ flux would suppress the crystal growth to some extent to yield smaller crystallites.

The crystallite size was also decreased with increasing the amount of La doping (Table 1, entries 10, 13, 15-17). Kudo et al., reported that La doping could suppress the crystal growth of $\mathrm{NaTaO}_{3}: \mathrm{La}$ during the preparation of the $\mathrm{NaTaO}_{3}$ sample in a solid state reaction (SSR) method [16]. Thus, the present result confirmed that the crystal growth could be suppressed by La doping also in the present flux method.

The BET specific surface area of the samples was measured and listed in Table 1, entries 2-17 and also depicted in Fig. S1, where a rough tendency could be confirmed that the BET specific surface area decreased with increasing the crystallite size as expected.

Fig. 3 shows the SEM images of the $\mathrm{NaTaO}_{3}: \mathrm{La}$ samples prepared by the flux method at various solute concentrations from 5 to 100 (i.e. with/without the flux), as well as the sample without La doping. The shape of the $\mathrm{NaTaO}_{3}: \mathrm{La}$ particles was changed with the presence of the flux; i.e., the samples prepared with the flux had the cubic or rectangular particles (Figs. 3a-d), while the sample prepared in the absence of the flux 
had the rounded particles (Fig. 3e). Among them, the sample prepared with the solute concentration of $70 \%$ exhibited the most clear cubic shape (Fig. 3c).

The average particle sizes of these samples were estimated from the SEM images and listed in Table 1. The average particle size of the La doped samples prepared with the flux was in the range of 160-216 nm, which did not systematically vary with the solute concentration (entries 7-11). It is clear that the observed particle size in the SEM images was larger than the crystallite size calculated from XRD profiles.-The samples prepared without flux (Fig. 3e) and without La doping (Fig. 3f) consisted of much larger average particle sizes such as 315 and $733 \mathrm{~nm}$, respectively.

In DR UV-Vis spectra of the $\mathrm{NaTaO}_{3}: \mathrm{La}$ samples, the adsorption band appeared at shorter wavelength than $320 \mathrm{~nm}$ (Fig. 4). From these spectra the bandgap of these samples were evaluated from Tauc plot [36] and listed in Table 1. The values for the $\mathrm{NaTaO}_{3}: \mathrm{La}$ samples were in the range of 4.12-4.16 eV. In addition the sample without $\mathrm{La}$ doping showed lower values such as 4.06 and $4.10 \mathrm{eV}$ (entries 13, and 15). It is found that the bandgap was not significantly but slightly increased with decreasing of the crystallite size as shown in Fig. $\mathbf{S 2}$

In the previous study, it was reported that the band gap and specific surface area of the $\mathrm{NaTaO}_{3}: \mathrm{La}$ photocatalysts prepared in a SSR method increased with an increase of the La content [9]. The present study confirmed that, in addition to the presence of the La doping, the decrease of the crystallite size would also enlarge the band gap. Among the $\mathrm{NaTaO}_{3}: \mathrm{La}(x, 1273,2)$ samples prepared with various solute concentrations, as they had similar amount of La doping as shown in Table 1, it is suggested that the shift of the band gap would originate from the variation of the crystallite size (Fig. S2). This means that 
the structure, both the crystallite size and the band structure, could be controlled by the solute concentration in the flux method.

\subsection{Photocatalytic activity}

\subsubsection{Effect of the hold temperature}

The photocatalytic activity of the prepared Pt loaded $\mathrm{NaTaO}_{3}: \mathrm{La}$ samples was evaluated. A representative time course of the products formation rate is shown in Fig. S3. The products were hydrogen and carbon dioxide only. The ratio of these two products was 3.8 after $210 \mathrm{~min}$, which was close to the ideal ratio of eq. 1 within the experimental error. Without irradiation, no product formation was observed in all the catalysts. The reaction lasted for a long time under photoirradiation without catalytic deactivation. Since platinum loading enhanced the reaction such as 4.6 times as shown in Table 1, entries 10 and 14, TON was tentatively calculated based on Pt. The TON was 53 for 210 min, which was clearly larger than unity. These clarified that this reaction over the $\mathrm{Pt} / \mathrm{NaTaO}_{3}: \mathrm{La}$ samples proceeded photocatalytically. The production rate varied with the samples as listed in Table 1, indicating that the photocatalytic activity of the photocatalyst varied with the structures and the properties.

Fig. 5 shows the effect of the hold temperature among the preparation parameters on the hydrogen production rate. The hydrogen production rate was evaluated after ca. 4 h from the start of the reaction. The $\mathrm{Pt} / \mathrm{NaTaO}_{3}: \mathrm{La}$ photocatalyst prepared with the low hold temperature at $1073 \mathrm{~K}$ provided low activity, while the photocatalysts prepared with the higher hold temperature than $1173 \mathrm{~K}$ gave drastically higher activity. The photocatalysts prepared with higher hold temperatures than $1173 \mathrm{~K}$ showed almost similar activity, which suggests that the temperature of $1173 \mathrm{~K}$ was enough to prepare the 
$\mathrm{NaTaO}_{3}:$ La photocatalysts by the flux method. The XRD pattern showed that the $\mathrm{NaTaO}_{3}$ crystallites were generated when prepared with the hold temperature higher than $1173 \mathrm{~K}$ (Fig. 1). This result clearly indicates that the generation of the $\mathrm{NaTaO}_{3}: \mathrm{La}$ phase is essential for achieving the high activity in the photocatalytic steam reforming of methane. Among these photocatalysts, the $\mathrm{Pt}(0.2) / \mathrm{NaTaO}_{3}: \mathrm{La}(70,1273,1)$ photocatalyst exhibited the highest hydrogen production rate, i.e. $1.4 \mu \mathrm{mol} \mathrm{min}^{-1}$.

\subsubsection{Effect of the La doping}

Effect of La doping on the hydrogen production rate was investigated in the photocatalytic steam reforming of methane over the $\mathrm{Pt}(0.03) / \mathrm{NaTaO}_{3}: \mathrm{La}(30,1273, y)$ photocatalysts prepared by the flux method with various La contents (Fig. 6, Table 1 entries 8, 15-17). The hydrogen formation rate was low $\left(0.02 \mu \mathrm{mol} \mathrm{min} \mathrm{m}^{-1}\right)$ over the photocatalyst without La doping, while La doping drastically improved the activity. Among these samples, the maximum hydrogen production rate $\left(1.2 \mu \mathrm{mol} \mathrm{min}{ }^{-1}\right)$ was achieved at the La doping amount of $1 \mathrm{~mol} \%$, and the further addition of La doping over 1 mol\% decreased the activity. In literature, the positive effects of the La doping on the $\mathrm{NaTaO}_{3}$ photocatalysts prepared by the SSR method have been reported for the photocatalytic water splitting [16] and the photocatalytic steam reforming of methane [9]. Here, it was found that the La doping was also effective for the improvement of the activity of the $\mathrm{NaTaO}_{3}$ photocatalysts prepared in the flux method.

As for the reason why the La doping enhanced the photocatalytic activity, some possibilities have been pointed out. Kudo et al. suggested that the presence of La suppressed the crystal growth to form smaller $\mathrm{NaTaO}_{3}$ crystals with fine steps on the surface, which would be advantageous compared to the much larger particles of the 
photocatalyst without La doping [16]. Yamakata et al. pointed out that the La doping could prolong the lifetime of photo-generated carriers (electron and hole), which would result in the high activity [40]. In our previous study, the substitutionally doped La cations would change the band structure as well as the specific surface area of the photocatalyst [9]. Actually, since both the crystallite size and the electronic band structure simultaneously varied with La doping, it is unclear which factor is the most substantial. However, it is obvious that the La doping would be advantageous for the photocatalytic activity in these photocatalytic reactions that proceed through the water activation, such as the water splitting and the photocatalytic steam reforming of methane.

\subsubsection{Effect of the Pt cocatalyst}

Loading of Pt cocatalyst also significantly enhanced the activity as mentioned above. Fig. 7 shows the effect of the loading amount of the Pt cocatalyst. Even at the low Pt loading such as $0.03 \mathrm{wt} \%$, the hydrogen production rate on the $\mathrm{Pt}(0.03) / \mathrm{NaTaO}_{3}: \mathrm{La}(70,1273,2)$ photocatalyst was high $\left(1.2 \mu \mathrm{mol} \mathrm{min}{ }^{-1}\right)$, which is 4.6 times higher than that of non-modified $\mathrm{NaTaO}_{3}: \mathrm{La}(70,1273,2)\left(0.26 \mu \mathrm{mol} \mathrm{min}{ }^{-1}\right)$. The increase of the Pt loading to $0.2 \mathrm{wt} \%$ slightly increased the activity, and the maximum rate for the hydrogen production was obtained at $0.2 \mathrm{wt} \%\left(1.3 \mu \mathrm{mol} \mathrm{min}{ }^{-1}\right)$. The further increase of the Pt loading to $1.0 \mathrm{wt} \%$ drastically suppressed the hydrogen production rate.

\subsubsection{Effect of the solute concentration}

Fig. 8 shows the hydrogen production rate with the $\mathrm{Pt} / \mathrm{NaTaO}_{3}: \mathrm{La}_{\text {photocatalysts }}$ prepared with various solute concentrations. Among the $\mathrm{Pt}(0.03) / \mathrm{NaTaO}_{3}: \mathrm{La}(x, 1273,2)$ photocatalysts, the highest activity was $1.2 \mu \mathrm{mol} \mathrm{min} \mathrm{m}^{-1}$ in the present condition, which 
was obtained with the photocatalyst prepared with the solute concentration of $70 \%$. The hydrogen production rate was 1.4 times higher than that on the photocatalyst prepared without the flux, i.e., the $\operatorname{Pt}(0.03) / \mathrm{NaTaO}_{3}: \mathrm{La}(100,1273,2)$ photocatalyst. However, the photocatalysts prepared with the solute concentration less than $50 \mathrm{~mol} \%$ exhibited lower activity than the photocatalyst prepared without the flux. In the low solute concentrations such as 5-30 mol\%, the activity did not depend on the solute concentration. Thus, it was elucidated that the flux method could be effective for the preparation of the highly active photocatalysts if the preparation parameter was optimized. As for the preparation of the $\mathrm{NaTaO}_{3}: \mathrm{La}$ photocatalyst in the present condition, the solute concentration around 70 mol\% should be desirable.

\subsection{Correlation between the particle size and the activity}

To investigate the key parameter for the photocatalytic activity, the hydrogen production rate listed in Table 1 was plotted against the particle size evaluated from the SEM images (Fig. S4), and the band gap determined by DR UV-visible spectra (Fig. S5), respectively. However, no clear correlation was observed between the hydrogen production rate and these parameters as shown in Figs. S4, and S5.

Fig. 9 shows the relationship between the crystallite size of the photocatalysts and the hydrogen production rate in the photocatalytic steam reforming of methane over them among the photocatalysts prepared in the flux method with various parameters, i.e., the $\mathrm{Pt}(0.03) / \mathrm{NaTaO}_{3}: \mathrm{La}(x, 1273,2) \quad$ photocatalysts (open circles), the $\mathrm{Pt}(0.2) / \mathrm{NaTaO}_{3}: \mathrm{La}(70, T, 1)$ photocatalysts, where $T=1173-1473 \mathrm{~K}$ (open squares), and the $\operatorname{Pt}(0.03) / \mathrm{NaTaO}_{3}: \mathrm{La}(30,1273, y)$ photocatalysts (open triangles), mentioned above (Table 1, entries 2-11, 16, and 17). Among the $\mathrm{Pt}(0.03) / \mathrm{NaTaO}_{3}: \mathrm{La}(x, 1273,2)$ 
photocatalysts prepared with various solute concentrations (open circles), a positive linear correlation was clearly observed between the crystallite size and the hydrogen production rate. The line in Fig. 9 was obtained by a least square fitting of the phots for the $\operatorname{Pt}(0.03) / \mathrm{NaTaO}_{3}: \mathrm{La}(x, 1273,2)$ photocatalysts. In addition, the plots for the $\mathrm{Pt}(0.2) / \mathrm{NaTaO}_{3}: \mathrm{La}(70, T, 1) \quad$ photocatalysts (open squares) and the $\mathrm{Pt}(0.03) / \mathrm{NaTaO}_{3}: \mathrm{La}(30,1273, y)$ photocatalysts (open triangles) were in alignment with the line. Thus, it was confirmed that the photocatalytic activity of the $\mathrm{Pt} / \mathrm{NaTaO}_{3}: \mathrm{La}$ photocatalysts prepared in the flux method strongly depended on the size of the $\mathrm{NaTaO}_{3}$ crystallites. These samples showing the good correlation actually included various samples with the composition, the structure and the electrical properties such as the La content, the particle size, and the band gap as shown in Table 1. This means that these parameters could not give a dominant effect on the photocatalytic activity, although these parameters would be related to the crystallite size and indirectly or slightly influence the photocatalytic activity.

The positive correlation between the photocatalytic activity and the crystallite size (or particle size) was reported by several groups in several multi-electron reactions; e.g., photocatalytic oxygen evolution from silver nitrate aqueous solutions [41, 42], and photocatalytic $\mathrm{CO}_{2}$ reduction [23]. Amano et al., reported that the recombination of the photogenerated carriers in the large $\mathrm{WO}_{3}$ particles was slower than that in the small particles, and it would be due to the fast surface recombination compared to the bulk [41]. Thus, the surface recombination is one possibility for the low activity of the present small $\mathrm{NaTaO}_{3}: \mathrm{La}$ crystallites because the surface-to-volume ratio would be high for small particles. Another possibility is that a large crystallite can absorb a larger number of photons than a small one due to its large irradiated area per one crystallite. In the case of 
the multi-electron reactions, the large number of the absorbed photons might effectively result in the high activity.

On the other hands, when we compared the photocatalytic activity over the photocatalysts having the same $\mathrm{NaTaO}_{3}: \mathrm{La}$ crystallite size, the activity of the $\mathrm{Pt}(0.03) / \mathrm{NaTaO}_{3}: \mathrm{La}(100,1273,2)$ photocatalyst prepared without the flux (closed diamond) was obviously lower than the line. In other words, the photocatalyst prepared with the flux exhibited higher activity than the photocatalyst prepared without the flux if the samples had the same size of the crystallites, which corresponded to 1.6 times higher activity. This suggests that the photocatalyst prepared without the flux would have negative parameters other than the crystallite size; i.e., the sample prepared with flux would have one or more positive factors for the efficient activity compared to that prepared without the flux.

As mentioned above, the photocatalysts prepared with the flux consisted of the cubic or rectangular particles, different from the roundish particles of the sample prepared without the flux. Thus, the merits of the photocatalyst prepared in the flux method would possibly originate from the morphology. One possibility is that the cubic or rectangular particles covered with the clear facets might be more beneficial for the efficient charge separation of the photo-excited carriers in the photocatalysts $[16,20]$. Another is that the clear shape particles might have high crystallinity with less crystal defects, which might result in the less recombination of the electron and hole pairs. The other is that the photocatalytic activity might depend on the population of the surface sites, such as edges and corners, that would be determined by the morphology [17]. Thus, the preferable morphology of the present photocatalyst prepared in the flux method would well promote the charge separation or reduce the recombination, or the cubic or rectangular shape with 
the regular surface structure might be desirable for the photocatalytic steam reforming of methane.

In several photocatalytic reactions, molecular adsorption properties could much affect the activity, where large surface area would provide the large adsorption/reaction sites $[43,44]$. However, in the present case, the increase of the specific surface area of the $\mathrm{NaTaO}_{3}: \mathrm{La}$ photocatalysts resulted in the decrease of the activity (see Table 1). This means that the contribution of the rate of these surface events (e.g., adsorption, surface reaction, and desorption) to the overall reaction rate would be smaller than that of the photo-related process such as the charge separation and migration to the surface.

\section{CONCLUSIONS}

The present study demonstrated the effectiveness of the flux method using a sodium chloride flux to synthesize a high-performance $\mathrm{Pt} / \mathrm{NaTaO}_{3}: \mathrm{La}$ photocatalyst for the photocatalytic steam reforming of methane. The flux method provided cubic or rectangular morphology of the $\mathrm{NaTaO}_{3}: \mathrm{La}$ particles. La doping drastically improved the photocatalytic activity even when the samples were prepared in the flux method. The optimized catalyst prepared by the flux method shows 1.6 times higher activity than the sample prepared without the flux when compared the catalysts having the same crystallite size.

Various $\mathrm{Pt} / \mathrm{NaTaO}_{3}:$ La particles were prepared by changing the preparation condition and the composition, such as the presence or absence of the flux, the solute concentration, the hold temperature, and the amount of the lanthanum doping and the platinum cocatalyst, and the relationship between the structural and physical properties and the photocatalytic activity was investigated. Among the preparation parameters in the flux method, the 
solute concentration much influenced the crystallite size of the $\mathrm{NaTaO}_{3}: \mathrm{La}$ samples; i.e., the crystallite size increased with increasing the solute concentration. It is notable that a positive correlation was observed between the $\mathrm{NaTaO}_{3}: \mathrm{La}$ crystallite size and the hydrogen production rate; in other words, the larger crystallite size gave the higher photocatalytic activity. Besides this correlation, we proposed the cubic or rectangular morphology of the $\mathrm{NaTaO}_{3}: \mathrm{La}$ photocatalysts would be effective for the steam reforming of methane by comparing the roundish shape of the photocatalyst prepared without the flux.

\section{ACKNOWLEDGMENT}

This work was partially supported by a Grant-in-Aid for Scientific Research (B), (No. 25289285), and a Grant-in-Aid for Scientific Research on Innovative Areas "Artificial photosynthesis (AnApple)" (No. 25107515) from the Japan Society for the Promotion of Science (JSPS).

\section{REFERENCES}

[1] L. Yuliati, H. Yoshida, Chem. Soc. Rev. 37 (2008) 1592-1602.

[2] K. Shimura, H. Yoshida, Catal. Surv. Asia. 18 (2014) 24-33.

[3] J. Baltrusaitis, I. Jansen, J.D. Schuttlefield Christus, Catal. Sci. Technol. 4 (2014) 2397-2411.

[4] C.E. Taylor, R.P. Noceti, Catal. Today 55 (2000) 259-267.

[5] C.E. Taylor, Catal. Today 84 (2003) 9-15.

[6] M.A. Gondal, A. Hameed, A. Suwaiyan, Appl. Catal. A 243 (2003) 165-174.

[7] H. Yoshida, S. Kato, K. Hirao, J. Nishimoto, T. Hattori, Chem. Lett. 36 (2007) 430-431.

[8] H. Yoshida, K. Hirao, J. Nishimoto, K. Shimura, S. Kato, H. Itoh, T. Hattori, J. Phys. Chem. C 112 (2008) 5542-5551.

[9] K. Shimura, S. Kato, T. Yoshida, H. Itoh, T. Hattori, H. Yoshida, J. Phys. Chem. C 114 (2010) 3493-3503. 
[10] K. Shimura, H. Miyanaga, H. Yoshida, Stud. Surf. Sci. Catal. 175 (2010) 85-92.

[11] K. Shimura, H. Yoshida, Energy Environ. Sci. 3 (2010) 615-617.

[12] K. Shimura, H. Kawai, T. Yoshida, H. Yoshida, Chem. Commun. 47 (2011) 89588960.

[13] K. Shimura, H. Kawai, T. Yoshida, H. Yoshida, ACS Catal. 2 (2012) 2126-2134.

[14] K. Shimura, T. Yoshida, H. Yoshida, J. Phys. Chem. C 114 (2010) 11466-11474.

[15] K. Shimura, K. Maeda, H. Yoshida, J. Phys. Chem. C 115 (2011) 9041-9047.

[16] H. Kato, K. Asakura, A. Kudo, J. Am. Chem. Soc. 125 (2003) 3082-3089.

[17] M. Farhadian, P. Sangpout, G. Hosseinzadeh, J. Energy Chem. 24 (2015) 171177.

[18] Z. Wei, E. Kowalska, J. Verrett, C. Colbeau-Justin, H. Remita, B. Ohtani, Nanoscale 7 (2015) 12392-12404.

[19] G. Liu, J.C. Yu, G.Q. Lu, H.-M. Cheng, Chem. Commun. 47 (2011) 6763-6783.

[20] R. Li, F. Zhang, D. Wang, J. Yang, M. Li, J. Zhu, X. Zhou, H. Han, C. Li, Nat. Commun. 4 (2013) 1432.

[21] T. Ohno, K. Sarukawa, M. Matsumura, New J. Chem. 26 (2002) 1167-1170.

[22] K. Iizuka, T. Wato, Y. Miseki, K. Saito, A. Kudo, J. Am. Chem. Soc. 133 (2011) 20863-20868.

[23] H. Yoshida, L. Zhang, M. Sato, T. Morikawa, T. Kajino, T. Sekito, S. Matsumoto, H. Hirata, Catal. Today 251 (2015) 132-139.

[24] K. Teshima, K. Horita, T. Suzuki, N. Ishizawa, S. Oishi, Chem. Mater. 18 (2006) 3693-3697.

[25] K. Teshima, Y. Niina, K. Yubuta, T. Suzuki, N. Ishizawa, T. Shishido, S. Oishi, Eur. J. Inorg. Chem. 2007 (2007) 4687-4692.

[26] K. Teshima, K. Yubuta, T. Shimodaira, T. Suzuki, M. Endo, T. Shishido, S. Oishi, Cryst. Growth Des. 8 (2008) 465-469.

[27] L. Zhen, C.Y. Xu, W.S. Wang, C.S. Lao, Q. Kuang, Appl. Surf. Sci. 255 (2009) 4149-4152.

[28] S. Lee, K. Teshima, Y. Niina, S. Suzuki, K. Yubuta, T. Shishido, M. Endo, S. Oishi, CrystEngComm 11 (2009) 2326-2331.

[29] S. Lee, K. Teshima, Y. Mizuno, K. Yubuta, T. Shishido, M. Endo, S. Oishi, CrystEngComm 12 (2010) 2871-2877.

[30] K. Teshima, S. Lee, A. Yamaguchi, S. Suzuki, K. Yubuta, T. Ishizaki, T. Shishido, S. Oishi, CrystEngComm 13 (2011) 1190-1196.

[31] J. Sun, G. Chen, Y. Li, R. Jin, Q. Wang, J. Pei, Energy Environ. Sci. 4 (2011) 4052-4060. 
[32] D. Arney, T. Watkins, P.A. Maggard, J. Am. Ceram. Soc. 94 (2011) 1483-1489.

[33] H. Kato, M. Kobayashi, M. Hara, M. Kakihana, Catal. Sci. Technol. 3 (2013) 1733-1738.

[34] H. Yoshida, M. Takeuchi, M. Sato, L. Zhang, T. Teshima, M.G. Chaskar, Catal. Today 232 (2014) 158-164.

[35] H. Kato, A. Kudo, J. Phys. Chem. B 105 (2001) 4285-4292.

[36] J. Tauc, R. Grigorovici, A. Vancu, Phys. Status Solidi B 15 (1966) 627-637.

[37] N.C. Stephenson, R.S. Roth, Acta Crystallogr., Sect. B: Struct. Sci., Cryst. Eng. Mater. 27 (1971) 1037-1044.

[38] J. Akella, S.N. Vaidya, G.C. Kennedy, Phys. Rev. 185 (1969) 1135-1140.

[39] M. Ahtee, L. Unonius, Acta Crystallogr., Sect. A: Found. Adv. 33 (1977) 150154.

[40] A. Yamakata, T. Ishibashi, H. Kato, A. Kudo, H. Onishi, J. Phys. Chem. B 107 (2003) 14383-14387.

[41] F. Amano, E. Ishinaga, A. Yamakata, J. Phys. Chem. C 117 (2013) 22584-22590.

[42] F. Amano, M. Nakata, Appl. Catal. B 158-159 (2014) 202-208.

[43] J.M. Herrmann, Top. Catal. 34 (2005) 49-65.

[44] H. Kominami, S. Murakami, J.-i. Kato, Y. Kera, B. Ohtani, J. Phys. Chem. B 106 (2002) 10501-10507. 
Table 1. Physical and optical properties of the $\mathrm{NaTaO}_{3}: \mathrm{La}$ samples prepared by the flux method and the photocatalytic performance of the $\mathrm{Pt} / \mathrm{NaTaO}_{3}: \mathrm{La}$ samples in the photocatalytic steam reforming of methane.

\begin{tabular}{|c|c|c|c|c|c|c|c|c|c|c|}
\hline Entry & $T^{a} / \mathrm{K}$ & $\begin{array}{c}\text { Solute } \\
\text { concentration } \\
(\mathrm{mol} \%)\end{array}$ & $\begin{array}{c}\text { Introduced } \\
\text { amount of } \mathrm{La}^{c} \\
(\mathrm{~mol} \%)\end{array}$ & $\begin{array}{l}\text { La content }^{d} \\
\qquad(\mathrm{~mol} \%)\end{array}$ & $\begin{array}{c}\text { Crystallite } \\
\text { size }(\mathrm{XRD})^{e} \\
/ \mathrm{nm}\end{array}$ & $\begin{array}{c}\text { Particle size } \\
\left(_{\text {SEM })^{f}}\right. \\
/ \mathrm{nm}\end{array}$ & $\begin{array}{l}S_{\mathrm{BET}^{g}} / \\
\mathrm{m}^{2} \mathrm{~g}^{-1}\end{array}$ & $\begin{array}{l}\text { Band gap }^{h} \\
\quad / \mathrm{eV}\end{array}$ & $\begin{array}{l}\text { Loading amount } \\
\text { of } \mathrm{Pt}(\mathrm{wt} \%)\end{array}$ & $\begin{array}{c}\mathrm{H}_{2} \text { production } \\
\text { rate }^{i} / \mu \mathrm{mol} \\
\mathrm{min}^{-1}\end{array}$ \\
\hline 1 & 1073 & 70 & 1 & - & $-{ }^{j}$ & - & - & - & 0.2 & 0.12 \\
\hline 3 & 1273 & 70 & 1 & - & 69 & - & 3.5 & - & 0.2 & 1.4 \\
\hline 4 & 1323 & 70 & 1 & - & 80 & - & 3.5 & - & 0.2 & 1.2 \\
\hline 5 & 1373 & 70 & 1 & - & 77 & - & 2.0 & - & 0.2 & 1.3 \\
\hline 7 & 1273 & 5 & 2 & 1.9 & 54 & 195 & 5.2 & - & 0.03 & 0.60 \\
\hline 8 & 1273 & 30 & 2 & 2.1 & 56 & 210 & 4.6 & 4.16 & 0.03 & 0.56 \\
\hline 9 & 1273 & 50 & 2 & 2.2 & 62 & 160 & 5.0 & 4.16 & 0.03 & 0.78 \\
\hline 10 & 1273 & 70 & 2 & 2.2 & 71 & 210 & 3.5 & 4.14 & 0.03 & 1.2 \\
\hline 11 & 1273 & 90 & 2 & 2.0 & 68 & 216 & 2.4 & 4.13 & 0.03 & 1.1 \\
\hline 12 & 1273 & 100 & 2 & 2.1 & 76 & 315 & 2.1 & 4.12 & 0.03 & 0.85 \\
\hline 13 & 1273 & 70 & 0 & - & 84 & 733 & 0.92 & 4.10 & 0.03 & 0.22 \\
\hline 15 & 1273 & 30 & 0 & - & 88 & - & 0.5 & 4.06 & 0.03 & 0.02 \\
\hline 16 & 1273 & 30 & 1 & 1.1 & 65 & - & 4.9 & 4.14 & 0.03 & 1.2 \\
\hline 17 & 1273 & 30 & 5 & 4.6 & 50 & - & 5.5 & 4.15 & 0.03 & 0.55 \\
\hline
\end{tabular}

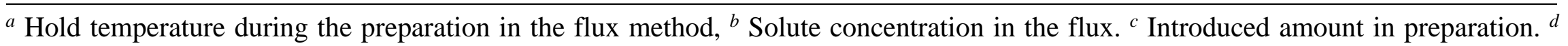
Doping amount of La measured with XRF. ${ }^{e}$ Average crystallite size calculated from a line width in the XRD patterns. ${ }^{f}$ Average particle size estimated from the SEM images. Relative standard deviations were ca. $60 \%{ }^{g}$ Specific surface area calculated in the BET method. ${ }^{h}$ Band gap determined by UV-vis adsorption spectra. ${ }^{i}$ The hydrogen production rate was evaluated at $4 \mathrm{~h}$ later from the start of photoirradiation. ${ }^{j} \mathrm{NaTaO}_{3}$ was not formed. ${ }^{k}$ The same data as those in the entry 10. 


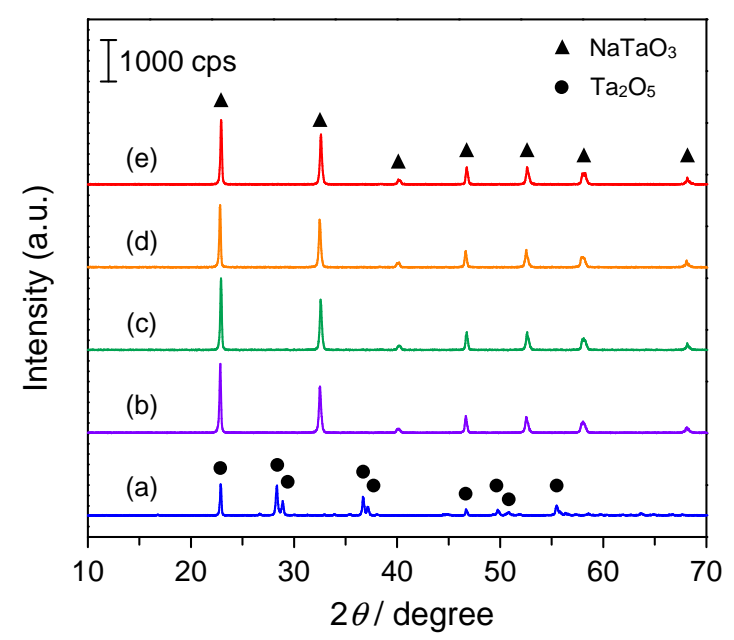

Fig. 1. XRD patterns of the $\mathrm{Pt}(0.2) / \mathrm{NaTaO}_{3}: \mathrm{La}(70, T, 1)$ samples prepared by the flux method at various hold temperature of (a) 1073, (b) 1173, (c) 1273, (d) 1373, and (e) 1473 $\mathrm{K}$. 


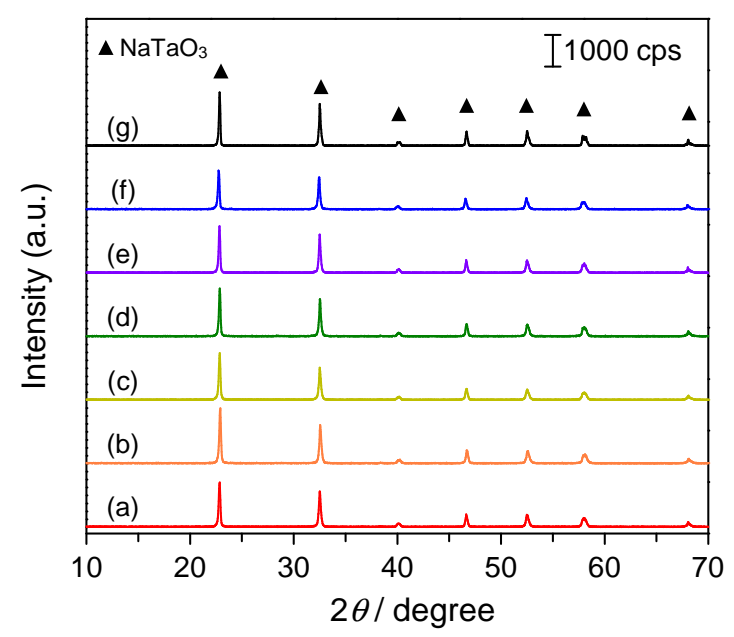

Fig. 2. XRD patterns of the $\mathrm{Pt}(0.03) / \mathrm{NaTaO}_{3}: \mathrm{La}(x, 1273,2)$ samples prepared by the flux method at various solute concentrations of (a) 5, (b) 30, (c) 50, (d) 70, (e) 90, and (f) 100 mol\%, and (g) the $\mathrm{Pt}(0.03) / \mathrm{NaTaO}_{3}(70,1273,0)$ sample without $\mathrm{La}$ doping. The $\mathrm{NaTaO}_{3}: \mathrm{La}(100,1273,2)$ sample was prepared without the flux. 


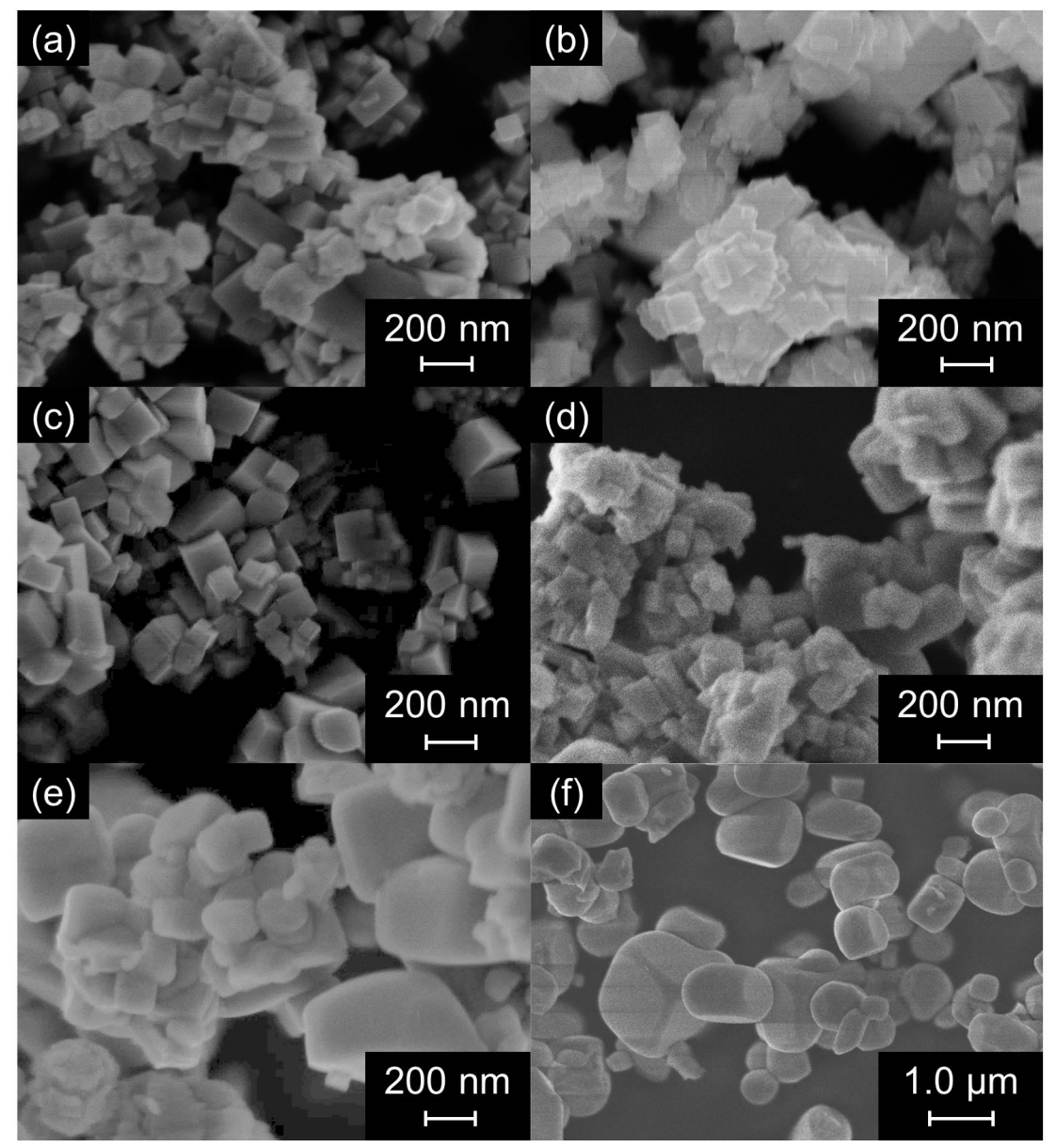

Fig. 3. SEM images of the $\mathrm{NaTaO}_{3}: \mathrm{La}(x, 1273,2)$ samples prepared by the flux method with various solute concentrations of (a) 5, (b) 30, (c) 70, (d) 90, and (e) 100 mol\%, where the $\mathrm{NaTaO}_{3}: \mathrm{La}(100,1273,2)$ sample was prepared without the flux, as well as (f) the $\mathrm{NaTaO}_{3}(70,1273,0)$ sample without La doping. 


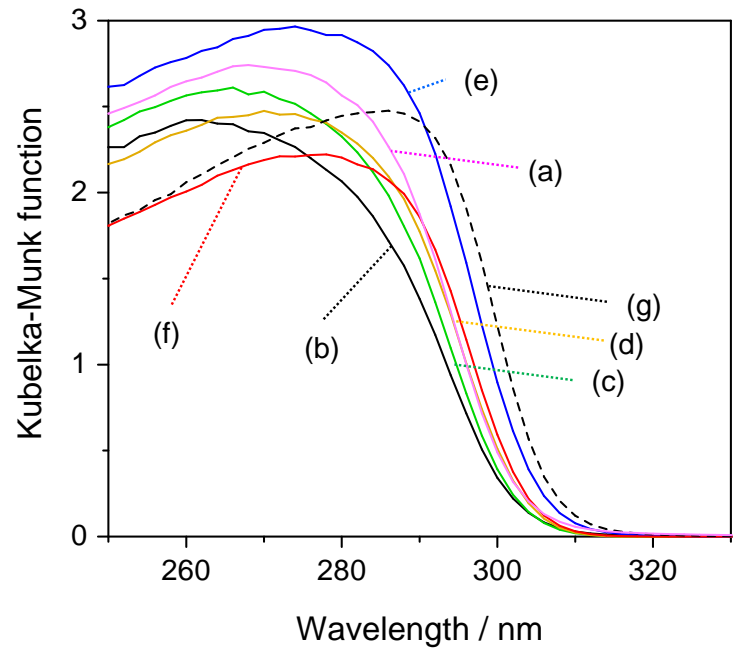

Fig. 4. DR UV-Vis spectra of the $\mathrm{NaTaO}_{3}: \mathrm{La}(x, 1273,2)$ samples prepared by the flux method at various solute concentrations of (a) 5, (b) 30, (c) 50, (d) 70, (e) 90, and (f) 100 mol\%, where the $\mathrm{NaTaO}_{3}: \mathrm{La}(100,1273,2)$ sample was prepared without the flux, and $(\mathrm{g})$ that of the $\mathrm{NaTaO}_{3}: \mathrm{La}(70,1273,0)$ sample prepared by the flux method without La doping. 


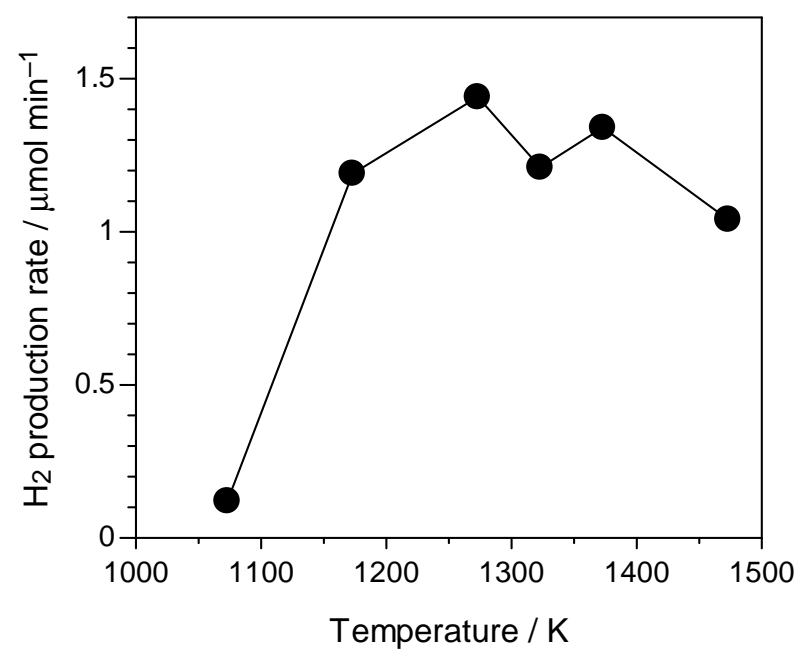

Fig. 5. The hydrogen production rate in the photocatalytic steam reforming of methane over the $\mathrm{Pt}(0.2) / \mathrm{NaTaO}_{3}(70, T, 1)$ photocatalysts prepared with various hold temperatures. The hydrogen production rate was evaluated at $4 \mathrm{~h}$ later from the start of photoirradiation. 


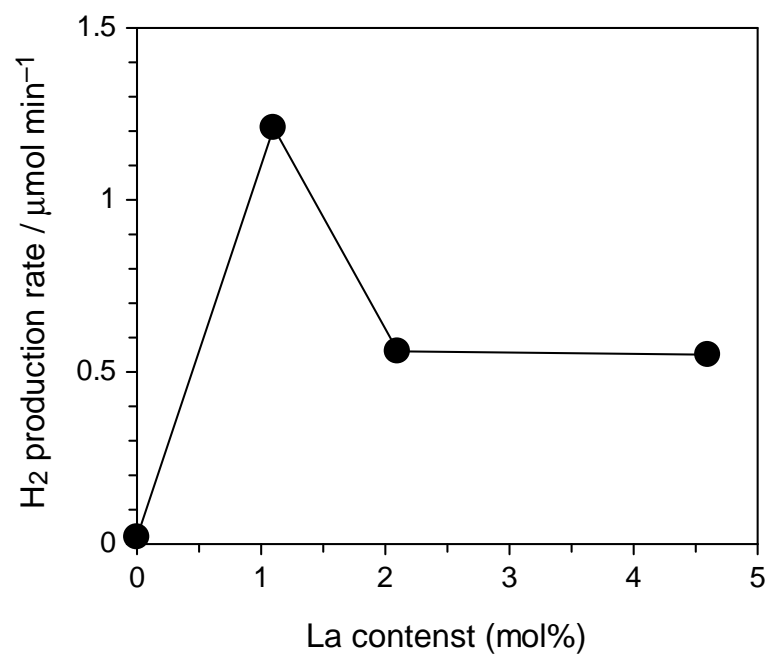

Fig. 6 The hydrogen production rate in the photocatalytic steam reforming of methane over the $\mathrm{Pt}(0.03) / \mathrm{NaTaO}_{3}: \mathrm{La}(30,1273, y)$ photocatalysts prepared by the flux method with various La contents. The La contents were measured with XRF. The hydrogen production rate was evaluated at $4 \mathrm{~h}$ later from the start of photoirradiation. 


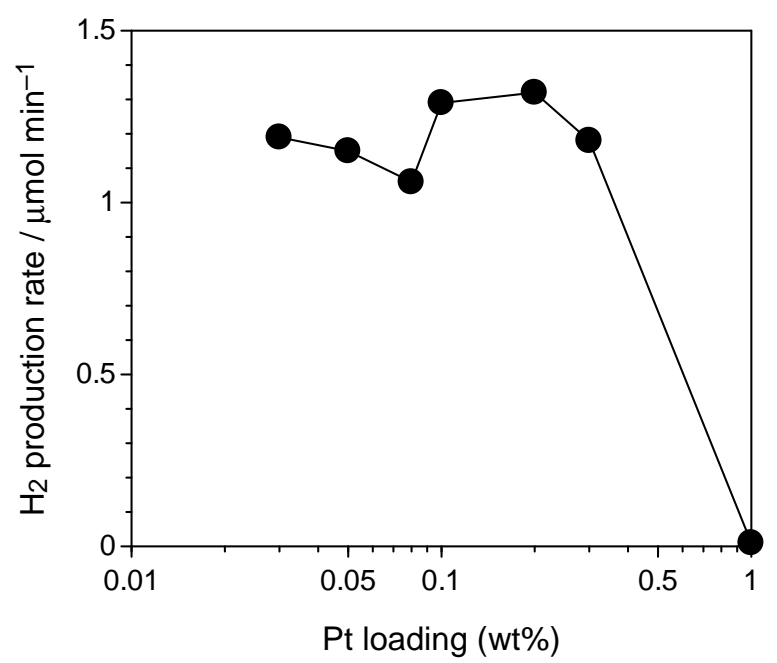

Fig. 7. The hydrogen production rate in the photocatalytic steam reforming of methane over the $\operatorname{Pt}(z) / \mathrm{NaTaO}_{3}(70,1273,2)$ photocatalysts with various $\mathrm{Pt}$ loading amount. The hydrogen production rate was evaluated at $4 \mathrm{~h}$ later from the start of photoirradiation. 


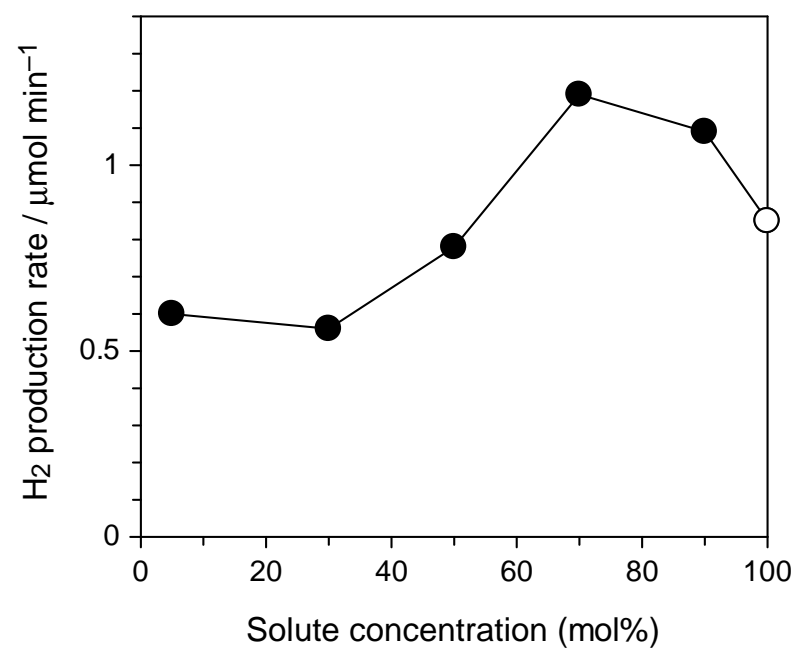

Fig. 8. The hydrogen production rate in the photocatalytic steam reforming of methane over the $\mathrm{Pt}(0.03) / \mathrm{NaTaO}_{3}: \mathrm{La}(x, 1273,2)$ photocatalysts prepared by the flux method at various solute concentrations. The plot at $100 \%$ for the solute concentration shows the value for the sample prepared without the flux. The hydrogen production rate was evaluated at $4 \mathrm{~h}$ later from the start of photoirradiation. 


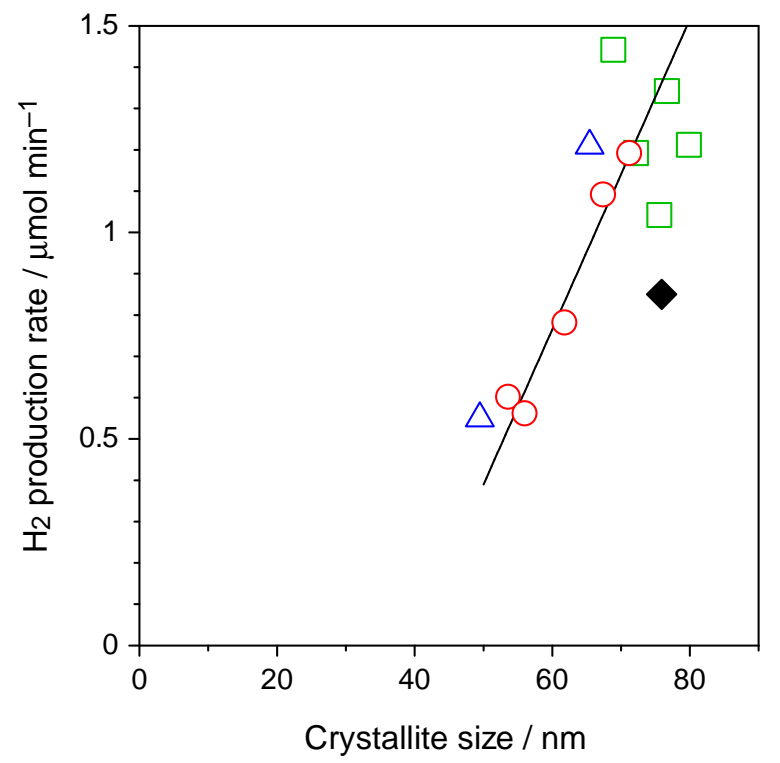

Fig. 9. Correlation between the hydrogen production rate in the steam reforming of methane and the crystallite size of $\mathrm{NaTaO}_{3}: \mathrm{La}$ in the photocatalysts. Open circles: the $\operatorname{Pt}(0.03) / \mathrm{NaTaO}_{3}: \mathrm{La}(x, 1273,2)$ photocatalysts prepared with various solute concentrations, open squares: the $\mathrm{Pt}(0.2) / \mathrm{NaTaO}_{3}: \mathrm{La}(70, T, 1)$ photocatalysts prepared with various high hold temperatures $(T=1173-1473 \mathrm{~K})$, open triangles: the $\mathrm{Pt}(0.03) / \mathrm{NaTaO}_{3}: \mathrm{La}(30,1273, y)$ photocatalysts with La contents $(y=1$ and 5), and a closed diamond: the $\mathrm{Pt}(0.03) / \mathrm{NaTaO}_{3}: \mathrm{La}(100,1273,2)$ photocatalysts prepared without the flux. The linear fitting was calculated from the plots of the $\mathrm{Pt}(0.03) / \mathrm{NaTaO}_{3}: \mathrm{La}(x, 1273,2)$ photocatalysts prepared with the various solute concentrations. The hydrogen production rate was evaluated at $4 \mathrm{~h}$ later from the start of photoirradiation. 